\title{
Immunoregulatory effects of AFP domains on monocyte-derived dendritic cell function
}

\author{
Agus Setiyono ${ }^{*}$, Akterono D Budiyati, Sigit Purwantomo, Madonna R Anggelia, Ismail Fanany, Gunawan A Wibowo, \\ Indra Bachtiar, Andi Utama, Susan Tai
}

\begin{abstract}
Background: Alpha-fetoprotein (AFP) is a tumor-associated glycoprotein that functions in regulation of both ontogenic and oncogenic growth. Recent study showed that AFP can induce apoptosis or impair monocytederived dendritic cell (MDDC) function. However, it is still unclear which AFP domain (D-AFP) plays major role in this function.

Results: As expected monocytes cultured in the presence of Granulocyte Macrophage-Colony Stimulating Factor (GM-CSF) and Interleukin-4 (IL-4) developed into MDDC. Up-regulation of HLA-DR and CD11c as well as loss of CD14 molecules could be observed. Full length AFP (FL-AFP), domain 2 AFP (D2-AFP) and D3-AFP, but not D1-AFP, significantly inhibited the expression of $\mathrm{HLA}-\mathrm{DR}{ }^{\text {high }} / \mathrm{CD} 11 \mathrm{c}^{\text {high }}$ and $\mathrm{CD} 80^{+} / \mathrm{CD} 86^{\text {high }}$ molecules. In contrast, CD83 expression was substantially down-regulated in all samples. Expression of CD40 was significantly suppressed by FL-AFP but not by any D-AFPs. Finally, both FL-AFP and D-AFP impaired the MDDC ability to secrete IL-12 (p70).
\end{abstract}

Conclusions: D2- and D3- but not D1-AFP extensively suppresses the MDDC function. All the recombinant AFP proteins impaired the ability of MDDC to secrete IL-12.

\section{Background}

Human alpha-fetoprotein (AFP) is a tumor-associated fetal glycoprotein that functions in regulation of both ontogenic and oncogenic growth [1]. It consists of 15 disulfide bridges located at positions equivalent to human albumin, leading to a three dimensional structure that is similar to human albumin [2]. One of the biological properties of AFP is its regulatory effects on immune responses. In hepatocellular carcinoma (HCC) patients with high levels of AFP, antigen presenting cells (APCs) are dysfunctional. This leads to the suppression of T- and B-cells response [3]. Dendritic cells (DCs) are the most potent APCs and are important for the initiation of the immune response against pathogens and tumors. In an in vitro experiment, Um et al. (2004) reported that AFP treatment of DCs reduced the ability of monocyte-derived DC (MDDC) to produce IL-12 and induces apoptosis of MDDC [4]. However, it is still unclear which domain of the AFP plays the important role in apoptosis or impairment of the DC functions.

\footnotetext{
* Correspondence: asetiyono@mrinstitute.org

Mochtar Riady Institute for Nanotechnology, Tangerang 15810, Indonesia
}

The aims of this study were to produce recombinant AFP domain (D-AFP) proteins in an Escherichia coli expression system and to investigate the immunoregulatory properties of each D-AFP and to compare them to full length (FL)-AFP. Secretion of IL-12 by MDDC after treatment with D-AFP and FL-AFP was also analyzed.

\section{Results}

Cloning, expression, and purification of alpha-fetoprotein domains

Several E. coli expressing plasmid constructs were made to generate the recombinant AFPs. Recombinant AFP plasmids containing domain 1 and domain 2 were made in accordance with Morinaga et al (1983) [domain 1: amino acids position 1-197, domain 2: amino acids position 198-389], and domain 3 was produced with amino acid positions 357-590 [5]. The N-terminal of recombinant D1-AFP and D2-AFP contain an extra 14 amino acid peptide (MASMTGGQQMGRDP) while D3-AFP contains additional 2 amino acids (MA). To aid the purification process, all recombinant proteins also have 6xHis tag in their C-terminal ends (LEHHHHHH). D-AFPs were successfully expressed by Isopropyl $\beta$-D-1-thiogalactopyranoside

\section{()




\section{(A)}

$M \frac{D 1}{+} \frac{D 2}{+} \frac{D 3}{+}$

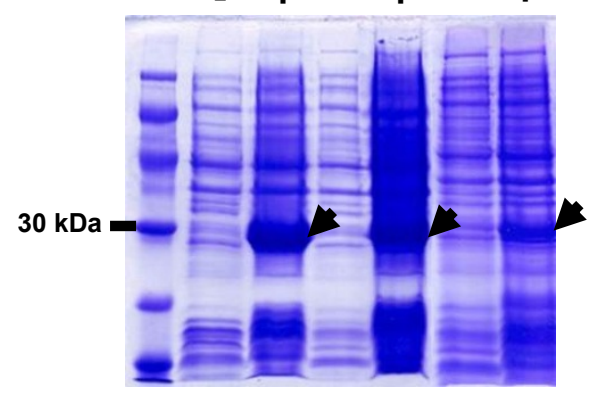

- : without IPTG

+ : with IPTG
(B)

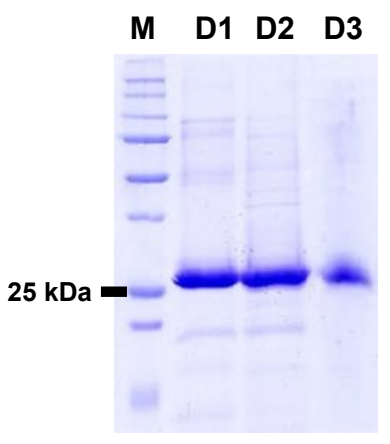

(C)

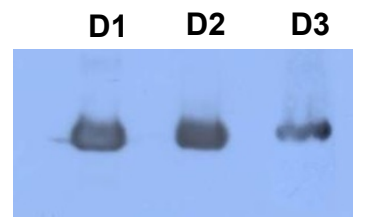

Figure 1 Purification of the AFP domains. (A) SDS-PAGE of total lysates without or with beta-gal induction (control and induction were denoted as - or + respectively). Gels were stained with Coomassie blue. M denotes protein marker. (B) Coomassie stained gels of purified proteins from each domain with molecular weight of $24.8 \mathrm{kDa}(\mathrm{D} 1)$ and $24.4 \mathrm{kDa}$ for D2 and D3. (C) Gel from B) was transferred to the nitrocellulose membrane and blotted with an anti-His antibody.

induction as confirmed by SDS-PAGE and Western blot using anti-His antibody (Figures $1 \mathrm{~A} \& 1 \mathrm{C}$ ). They were successfully purified by Ni-NTA column (Figure 1B).

\section{Impact of the domains on MDDC maturation in vitro}

As shown in Table 1 and Figure 2, freshly isolated monocytes from human PBMC (day 0) were CD14 ${ }^{+}$. After stimulation with GM-CSF, IL-4 and LPS, a high expression level of CD83 (day 8) (80.97 \pm 2.28 ) was seen, showing that MDDC was successfully derived from blood monocytes. At the same time, up-regulation of HLA-DR and CD11c as well as loss of CD14 molecules were also observed at day 8 (Figure 2B).

Addition of AFP has previously been shown to induce apoptosis of MMDC [4]. We added a range of AFP concentration between $1.56 \mu \mathrm{g} / \mathrm{ml}$ to $25 \mu \mathrm{g} / \mathrm{ml}$ and observed that MMDC cells start to die at FL-AFP concentration $>12.5 \mu \mathrm{g} / \mathrm{ml}$ (Figure 3 ). We thus chose the $6.25 \mu \mathrm{g} / \mathrm{ml}(0.091 \mu \mathrm{M})$ as the working concentration for most of the subsequent experiments. When AFP at concentration $6.25 \mu \mathrm{g} / \mathrm{ml}$ was added to the monocytes culture (day 0 ), a reduction of the mean expression level of

Table 1 Comparison of the phenotypic characteristic of MDDC at three stages dependent on treatments

\begin{tabular}{|c|c|c|c|c|c|c|}
\hline & & \multicolumn{5}{|c|}{ Surface Marker Expression (\%) } \\
\hline & & $\mathrm{CD}^{+} 4^{+}$ & $\begin{array}{l}\text { HLA-DR } \\
\text { /CDigh } 11 c^{\text {high }}\end{array}$ & $\begin{array}{c}\mathrm{CD}^{+} 0^{+} \\
/ \mathrm{CD} 86^{\text {high }}\end{array}$ & $\mathrm{CD} 40^{+}$ & $\mathrm{CD}^{2} 3^{+}$ \\
\hline & Monocytes* & $91.03 \pm 0.75$ & $42.70 \pm 2.04$ & $0.03 \pm 0.03$ & $22.83 \pm 9.92$ & $2.20 \pm 0.70$ \\
\hline \multirow[t]{2}{*}{ Non Treated } & imMDDC & $5.80 \pm 2.91$ & $67.47 \pm 3.94$ & $1.33 \pm 0.10$ & $52.47 \pm 14.98$ & $15.83 \pm 6.70$ \\
\hline & mMDDC & $5.17 \pm 0.82$ & $91.4 \pm 3.12$ & $92.57 \pm 1.52$ & $96.30 \pm 0.75$ & $80.97 \pm 2.28$ \\
\hline \multirow[t]{2}{*}{ FL-AFP } & imMDDC & $1.30 \pm 0.60$ & $47.73 \pm 4.45$ & $2.47 \pm 0.43$ & $38.50 \pm 7.30$ & $10.33 \pm 2.68$ \\
\hline & mMDDC & $1.47 \pm 0.57$ & $53.70 \pm 3.94^{* *}$ & $17.67 \pm 2.35^{* *}$ & $65.57 \pm 0.30^{* *}$ & $27.17 \pm 3.94^{* *}$ \\
\hline \multirow[t]{2}{*}{ D1-AFP } & imMDDC & $2.40 \pm 1.47$ & $56.27 \pm 2.50$ & $3.50 \pm 0.79$ & $54.80 \pm 11.47$ & $12.30 \pm 2.10$ \\
\hline & mMDDC & $1.87 \pm 0.38$ & $73.63 \pm 4.76$ & $65.47 \pm 7.03$ & $90.07 \pm 3.66$ & $59.27 \pm 8.90$ \\
\hline \multirow[t]{2}{*}{ D2-AFP } & imMDDC & $1.07 \pm 0.17$ & $44.30 \pm 2.04$ & $6.37 \pm 1.09$ & $63.53 \pm 10.02$ & $17.10 \pm 3.65$ \\
\hline & mMDDC & $2.40 \pm 0.40$ & $41.57 \pm 6.20^{* *}$ & $28.20 \pm 4.59^{* *}$ & $87.63 \pm 5.51$ & $34.70 \pm 3.43^{* *}$ \\
\hline \multirow[t]{2}{*}{ D3-AFP } & imMDDC & $1.90 \pm 0.53$ & $48.27 \pm 2.28$ & $6.90 \pm 1.65$ & $66.30 \pm 9.89$ & $21.97 \pm 5.88$ \\
\hline & mMDDC & $2.07 \pm 0.09$ & $43.80 \pm 6.91^{* *}$ & $27.47 \pm 4.06^{* *}$ & $85.27 \pm 4.89$ & $39.27 \pm 6.21^{* *}$ \\
\hline
\end{tabular}

* ImMDDC is immature MDDC. mMDDC is mature MDDC. Generation of each cell is described in the "Methods".

${ }^{* *}$ showed significant differences compare to non-treated (Tukey test, $p<0.05$ ). 
A

B
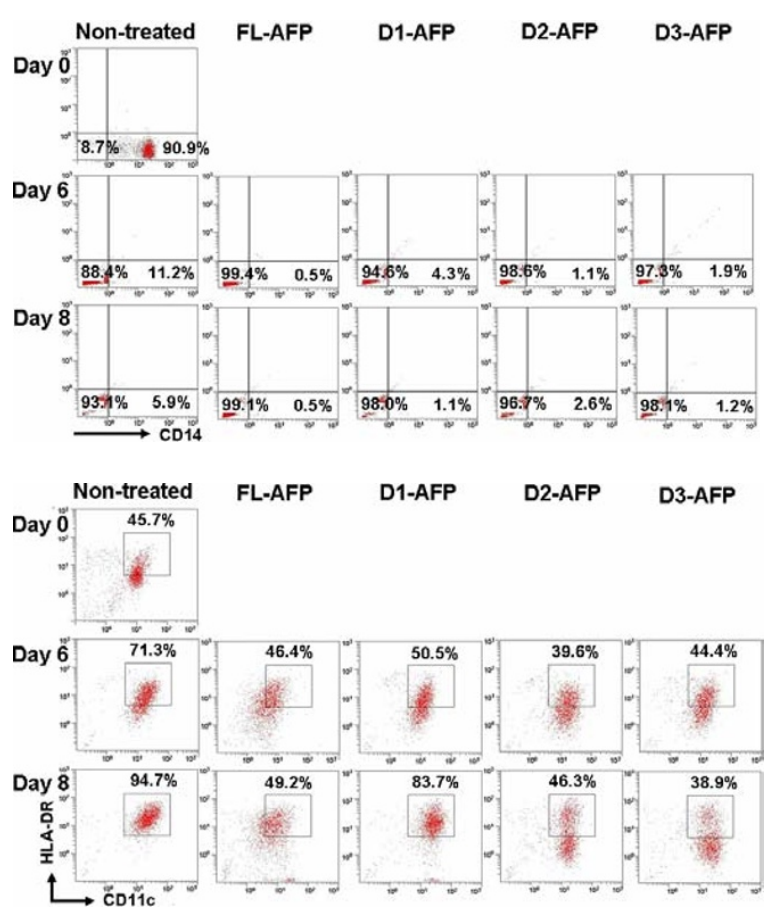

C
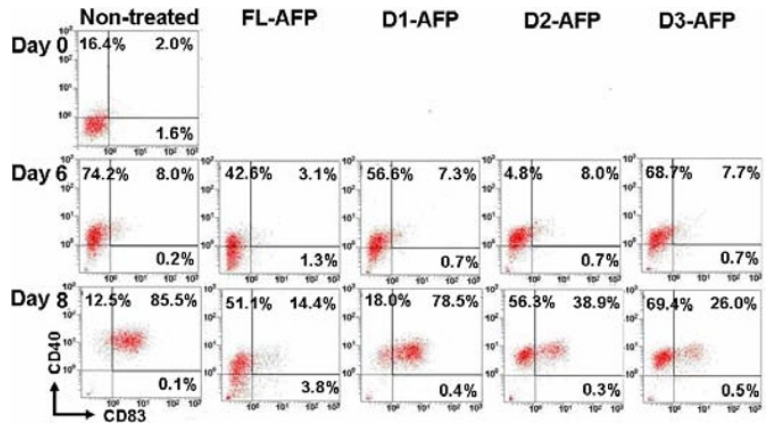

D

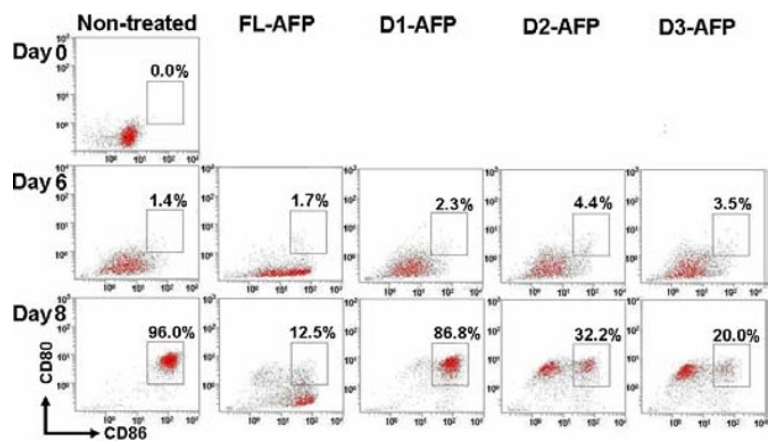

Figure 2 Effect of AFP domains on MDDC maturation and function in vitro. (A) CD14 expression pattern during DC maturation. Examination of surface markers for (B) HLA-DR and CD11C, (C) CD40 and CD83, and (D) CD80 and CD86 to monitor MDDC function.

CD83 was observed [from $80.97 \%$ to $27.17 \%$ in one experiment and $75.6 \%$ to $23 \%$ in another (Table 1 and 2 )]. The same effect was seen for CD80 (Table 2). The AFP immunoregulatory activity is dose-dependent as less suppression was seen at lower AFP concentrations (Table 2).
When individual AFP domain proteins were added at $0.091 \mu \mathrm{M}, \mathrm{D} 1$-AFP exhibited little suppressive effect on CD83 (59.27 \pm 8.90$)$. In contrast, D2-AFP and D3-AFP showed the same suppressive activities as the full-length AFP protein (Table 1). We concluded that D2-AFP and 


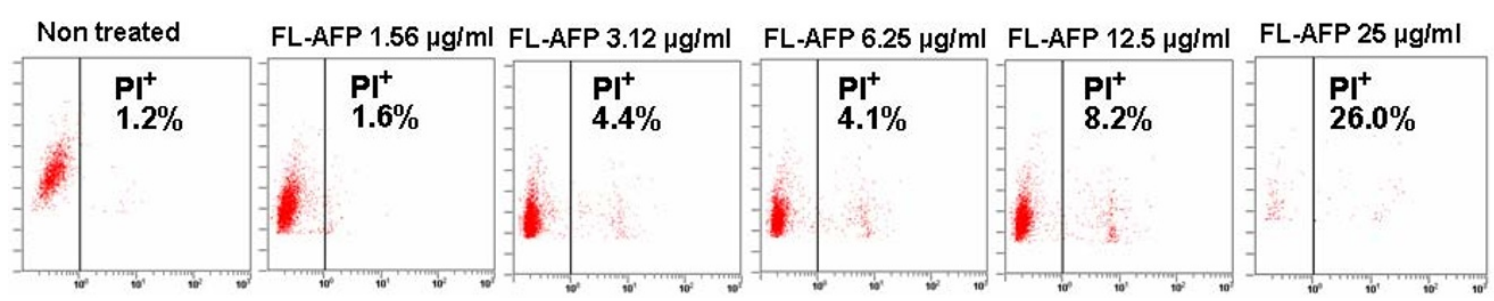

Figure 3 FL-AFP reduced the viability of MDDC population at high concentrations. Addition of AFP $12.50 \mu \mathrm{g} / \mathrm{ml}$ or above resulted in a significant cell death of MDDC population based on propidium iodide (PI) assay. PI staining was performed on MDDC culture at day 8, and analyzed with flow cytometry. The viability of MDDC was determined as percentage of negative PI cells. The graphics shown are a representative of three experiments with similar results.

D3-AFP could significantly block the maturation process of MDDC.

\section{Impact of the domains on MDDC function in vitro}

HLA-DR and CD11c were then used for further MDDC characterization. In the presence of $0.091 \mu \mathrm{M}$ D2-AFP or D3-AFP, MDDC culture failed to up-regulate HLADR. In contrast, $0.091 \mu \mathrm{M}$ D1-AFP treated MDDC culture showed high level of HLA-DR expression. The effect of D2-AFP and D3-AFP on the expression of HLA-DR ${ }^{\text {high }}$ was similar to the FL-AFP molecules (Figure 2B). Consistent with the HLA-DR results, expression of CD11c molecule was suppressed at day 8 by fulllength AFP $(53.70 \pm 3.94)$. The expression of HLA$\mathrm{DR}^{\text {high }} / \mathrm{CD} 11 \mathrm{c}^{\text {high }}$ was found to be repressed by D2-AFP $(41.57 \pm 6.20)$ and D3-AFP $(43.80 \pm 6.91)$ at day 8 (Table $1)$. This indicated that both D2-AFP and D3-AFP showed a similar suppressive effect to the expression of HLA$\mathrm{DR}^{\text {high }} / \mathrm{CD} 11 \mathrm{c}^{\text {high }}$ as the full-length AFP molecules.

In the absence of AFP or domains, CD40 was highly expressed after LPS induction (day 8) as shown in Figure 2. In contrast, addition of $0.091 \mu \mathrm{M}$ AFP repressed the ability of MDDC to express CD40 as shown in Table 1 (65.57 \pm 0.30 ) at day 8 (bottom panel). In the presence of $0.091 \mu \mathrm{M}$ D2-AFP or D3-AFP, CD40 expression was altered when compared to non-treated group. However, it was shown that number of $\mathrm{CD} 40^{+} / \mathrm{CD}^{2} 3^{+}$cells was reduced by
D2-AFP and D3-AFP but not D1-AFP (Figure 2C). We concluded that the expression of $\mathrm{CD} 40^{+}$and $\mathrm{CD} 83^{+}$on MDDC was suppressed when the D2-AFP or D3-AFP was present.

As shown in Figure 2D, after LPS induction, expression of $\mathrm{CD} 80^{+} / \mathrm{CD} 86^{\text {high }}$ was significantly inhibited by $0.091 \mu \mathrm{M}$ D2-AFP $(28.20 \pm 4.59)$ or D3-AFP $(27.47 \pm$ 4.06) in a similar effect to the full-length AFP protein $(17.67 \pm 2.35)$. In combination with HLA-DR ${ }^{\text {high }}$ expression, we concluded that the presence of D2-AFP or D3-AFP is likely to block the ability of MDDC to present antigens. We found that there was no significant difference in the expression of $\mathrm{CD} 80^{+} / \mathrm{CD} 86^{\text {high }}$ when D1-AFP is present during MDDC maturation.

\section{Effect of FL-AFP or D-AFP on IL-12 secretion}

Level of cytokine IL-12 (p70) in supernatant of each MDDC culture was measured using ELISA at day 6 (immature MDDC) and after $48 \mathrm{hrs}$ stimulation with LPS (mature MDDC). Before LPS stimulation, there was very low IL-12 produced by both non-treated and treated group (Table 3). After 48 hrs of LPS stimulation, a significant increase of IL-12 production was detected in the non-treated group but not in the groups treated by FL-AFP or any of the D-AFP samples. These results suggested that both FL-AFP and D-AFP can impair the ability of MDDC to produce IL-12 (p70).

Table 2 The viability of MDDC and expression of some surface markers on the mature MDDC treated with FL-AFP at different concentration

\begin{tabular}{|c|c|c|c|c|c|}
\hline & \multicolumn{2}{|c|}{ Cell viability (\%) } & \multicolumn{3}{|c|}{ Surface marker expression (\%) } \\
\hline & $\mathrm{PI}^{+}$ & PI- & $\mathrm{CD}^{2} 0^{+}$ & $\mathrm{CD}^{+} 6^{+}$ & $\mathrm{CD}^{2+}{ }^{+}$ \\
\hline Non Treated & $1.7 \pm 1.0$ & $98.3 \pm 1.0$ & $92.3 \pm 5.8$ & $99.4 \pm 0.6$ & $75.6 \pm 24.1$ \\
\hline FL-AFP $1.56 \mu \mathrm{g} / \mathrm{ml}$ & $2.4 \pm 1.7$ & $97.6 \pm 1.7$ & $77.1 \pm 20.1$ & $98.8 \pm 1.1$ & $48.4 \pm 21.7$ \\
\hline FL-AFP $3.12 \mu \mathrm{g} / \mathrm{ml}$ & $3.3 \pm 2.2$ & $96.7 \pm 2.2$ & $56.3 \pm 27.5$ & $99.1 \pm 0.4$ & $36.3 \pm 21.8$ \\
\hline FL-AFP $6.25 \mu \mathrm{g} / \mathrm{ml}$ & $3.5 \pm 1.1$ & $96.5 \pm 1.1$ & $30.9 \pm 28.7^{*}$ & $98.7 \pm 0.8$ & $23.0 \pm 19.8^{*}$ \\
\hline FL-AFP $12.5 \mu \mathrm{g} / \mathrm{ml}$ & $10.9 \pm 5.8$ & $89.1 \pm 5.8$ & $31.4 \pm 12.6^{*}$ & $92.4 \pm 10.2$ & $38.1 \pm 14.7$ \\
\hline FL-AFP $25 \mu \mathrm{g} / \mathrm{ml}$ & $28.2 \pm 10.2^{*}$ & $71.8 \pm 10.2^{*}$ & $30.0 \pm 0.2^{*}$ & $89.7 \pm 9.8$ & $2.5 \pm 1.6^{*}$ \\
\hline
\end{tabular}

* showed significant differences compare to non treated (Tukey test, $p<0.05$ ). 
Table 3 Production of IL 12 during MDDC maturation process

\begin{tabular}{lcc}
\hline Treatment & \multicolumn{2}{c}{ IL12 $\mathbf{p g} / \mathbf{m l})$} \\
\cline { 2 - 3 } & imMDDC & mMDDC \\
\hline Non Treated & $4.63 \pm 2.68$ & $148.13 \pm 85.52$ \\
FL-AFP & $1.60 \pm 0.92$ & $0.67 \pm 0.38$ \\
D1-AFP & $1.00 \pm 0.58$ & $3.63 \pm 2.10$ \\
D2-AFP & $1.80 \pm 1.04$ & $3.67 \pm 2.12$ \\
D3-AFP & $5.03 \pm 2.91$ & $1.37 \pm 0.79$ \\
\hline
\end{tabular}

\section{Discussion}

We investigated the effects of AFP domains on MDDC biology in vitro. The study was started by evaluating the effects of AFP full length (FL-AFP) on the viability of MDDC generated from healthy individuals. Using the E. coli system and purification procedure as previously reported [5], we could produce the domains of AFP in E. coli. In this study, we have delineated the AFP domains that execute the suppressive effect to MDDC maturation. Furthermore, we were interested to see whether after maturation, the MDDC can still function in the presence of the AFP domains. For antigen presentation, the engagement of the $\mathrm{T}$-cell receptor by peptide/MHC complexes (signal 1) is not sufficient to trigger a $\mathrm{T}$ cell response, and that ligation of a costimulatory receptor (signal 2) is required for $\mathrm{T}$ cell activation [6]. In addition, CD40 is also necessary for DC activation [7-10]. Binding CD40 with CD40 ligand will trigger downstream functions of DC such as cytokine secretion. We divided the MDDC functions into the ability to present the antigen and to secrete the cytokine by monitoring the expression of $\mathrm{CD} 14^{+}, \mathrm{CD} 83^{+}$, HLA$\mathrm{DR}^{\text {high }} / \mathrm{CD} 11 \mathrm{c}^{\text {high }}, \mathrm{CD} 40^{+} / \mathrm{CD} 3^{+}, \mathrm{CD} 80^{+} / \mathrm{CD} 86^{\text {high }}$ and IL-12 as shown in Table 1 and 2.

Differentiation of monocytes into MDDC was monitored by the expression of CD14 and CD83 molecule. During MDDC maturation, CD14 decreases and conversely, CD83 rapidly increases after addition of LPS. The presence of AFP molecule at the concentration $6.25 \mu \mathrm{g} / \mathrm{ml}$ $(0.091 \mu \mathrm{M})$ resulted in reduction of CD83 expression. Our results showed that the D2-AFP and D3-AFP retained the suppression effect on CD83 appearance. The suppression effect of D2-AFP and D3-AFP was found to be similar to FL-AFP during the maturation process. As MDDC maturation was repressed, we predict that the function of MDDC would also be suppressed if we added the D2-AFP and D3-AFP.

As shown in Table 1, cells that expressed HLA$\mathrm{DR}^{\text {high }} / \mathrm{CD} 11 \mathrm{c}^{\text {high }}, \mathrm{CD} 40^{+} / \mathrm{CD}^{2} 3^{+}$, and $\mathrm{CD} 80^{+} / \mathrm{CD} 86^{\text {high }}$ were significantly lower in the presence of D2-AFP and D3-AFP but comparable to the AFP molecules. This finding suggests that these two domains contain the suppression function to MDDC maturation and that
D2-AFP or D3-AFP potentially could be used for further study to unravel the role of AFP in the immune system.

Secretion IL-12 in the form of the biologically active p70 molecule could be considered to be one of the most important functions of DCs. IL-12p70 produced by DCs can polarize $\mathrm{T}$ cell responses towards $\mathrm{CD} 4+\mathrm{T}$ helper 1 cells (Th1). Th1 cells can support development of CD8+ cytotoxic $\mathrm{T}$ lymphocytes and in turn, can foster an appropriate adaptive immune response to eliminate malignant cells [11]. It has been reported that LPS from E. coli could induce MDDC to produce IL-12p70 [12]. However in the presence of the full-length AFP or AFP domains, the production was blocked. These data suggest a differential function of AFP domains in MDDC maturation and cytokine secretion.

AFP is a glycoprotein protein. The recombinant AFP fragments used in our study were expressed in E. coli, which does not have a glycosylation system. It is interesting to note that they were still functional in regulating MDDC function similarly to the full-length AFP derived from purified human cord blood serum, which presumably are glycosylated. These results indicated that glycosylation of AFP seems to be unnecessary in their immunoregulatory function. Our result was also supported by a study on the effect of glycosylation on AFP foldability and conformational structure performed by others [13]. Using reversed-phase column HPLC to analyze two AFP variants: glycosylated cord blood-derived AFP and non-glycosylated recombinant AFP purified from transgenic goat milk, they showed that glycosylation is not required for proper protein folding of the human AFP recombinant proteins. They presumed that this is due to the presence of only one single glycosylation site in human AFP [2] and glycosylation does not have a significant impact on the hydrophobicity or disulfide conformation of the molecule.

It has been reported that DC can be transfected or pulsed with antigens to enhance cytotoxic lymphocyte (CTL) responses [14]. In the context of DC-based immunotherapy, AFP has been considered as a candidate antigen to elicit effective tumor rejection $[15,16]$ but its suppressive activities on DC function have precluded its implementation. Our results indicated that individual AFP domains have differential effects on MDDC maturation and function with D1-AFP having the least suppressive activities. D1-AFP can thus potentially be used as an antigen to pulse MDDC to enhance CTL response against AFP. However, further investigations in vitro and in vivo are still needed to test this idea.

\section{Conclusions}

In conclusion, the AFP domains indeed have differential immunoregulatory function. In the context of MDDC 
maturation process, D2-AFP and D3-AFP have similar suppressive function as the full-length AFP molecule. As D1-AFP has no effect on DC function, it is a prime candidate for use in a DC-based immunotherapy.

\section{Methods}

\section{Cloning and expression of the AFP domains}

A complete AFP cDNA including its 5'-untranslated region (5'-UTR) was synthesized by reverse-transcription polymerase chain reaction (RT-PCR) from HepG2 total RNA. RT-PCR was performed using Access Quick RTPCR System (Promega, Wisconsin, USA) with specific AFP primers (forward primer F1: 5'-CTAAGGATCCATGAAGTGGGTGGAATC-3' and reverse primer R3: 5'- GAGAATTCTTAAACTCCCAAAGCAGCACGAG$\left.3^{\prime}\right)$. The resulting fragment was directly cloned into the TOPO 2.1 vector (Invitrogen, CA, USA). The pET21b clones containing D1 and D2 were verified by sequencing. All the fusion proteins contain 14 amino acid (aa) at their N-terminal ends (MASMTGGQQMGRDP) and 8 aa at their C-terminal ends (LEHHHHHH) derived from pET21b vector. For D3 construct, pET21d was used as a backbone (NcoI/XhoI). E. coli DH5 $\alpha$ and BL21 (DE3) were utilized for maintenance and expression, respectively. Expression of proteins was induced by Isopropyl $\beta$-D-1-thiogalactopyranoside (IPTG) and confirmed by ECL ${ }^{\text {ma }}$ Western Blotting Detection Systems (GE Healthcare, Uppsala, Sweden) using anti-His antibody according to manufacturer's protocol.

\section{Isolation, refolding, and purification}

Recombinant D-AFPs were purified based on previous report [5] with some modifications. Frozen cell pellet from $200 \mathrm{ml}$ culture was resuspended in $1 \mathrm{ml}$ buffer B (0.02 M Tris-Cl, $0.3 \mathrm{M} \mathrm{NaCl}, \mathrm{pH} 8.0)$. The cell suspension was sonicated on an ultrasonic disintegrator high intensity ultrasonic processor $750 \mathrm{~W}$ series (Sonics and Materials, Danbury, USA) $\left(12 \times 5 \mathrm{~s}, 4^{\circ} \mathrm{C}\right)$ and centrifuged $\left(12,000 \mathrm{~g}, 10 \mathrm{~min}, 4^{\circ} \mathrm{C}\right)$. The pellet was resuspended in $1.6 \mathrm{ml}$ buffer $\mathrm{B}$ and centrifuged $\left(12,000 \mathrm{~g}, 10 \mathrm{~min}, 4^{\circ} \mathrm{C}\right)$. This procedure was repeated five times. $1.3 \mathrm{ml}$ buffer A (0.1 M Tris- $\mathrm{Cl}$ buffer, $6 \mathrm{M}$ guanidine chlorides, $\mathrm{pH}$ 8.0) was used to wash bacterial inclusion bodies continued with sonication $\left(12 \times 5 \mathrm{~s}, 4^{\circ} \mathrm{C}\right)$ and centrifuged $(12,000 \mathrm{~g}$, $\left.30 \mathrm{~min}, 4^{\circ} \mathrm{C}\right)$. The supernatant was collected and filtered with a Millex-HV PVDF $0.45 \mu \mathrm{m}$ (Millipore, Massachusetts, USA) and applied onto $2 \mathrm{ml} \mathrm{Ni-NTA}$ superflow column (Invitrogen, Carlsbad, USA). The sorbent was washed consecutively with $3.3 \mathrm{ml}$ buffer A and $3.3 \mathrm{ml}$ buffer $\mathrm{C}(0.05 \mathrm{M}$ Tris-Cl, $6 \mathrm{M}$ Urea, $0.4 \mathrm{M} \mathrm{NaCl}$, and $0.02 \mathrm{M}$ Imidazole, $\mathrm{pH}$ 8.0). The protein was eluted in $2 \mathrm{ml}$ buffer D $(0.05 \mathrm{M}$ Tris- $\mathrm{HCl}, 6 \mathrm{M}$ Urea, $0.4 \mathrm{M} \mathrm{NaCl}$, and $0.3 \mathrm{M}$ Imidazole, $\mathrm{pH}$ 8.0). Each fraction from column was collected and analyzed by SDS-PAGE. The D fraction was further concentrated on Amicon stirred cell supplied with a PM-10 membrane (MW cutoff $10 \mathrm{kDa}$ ) (Millipore, Massachusetts, USA), and clarified through a Millex-HV PVDF $0.45 \mu \mathrm{m}$ membrane filter.

Beta-mercaptoethanol was added at the final concentration of $0.1 \mathrm{M}$ and incubated for $1 \mathrm{~h}$ at room temperature with continuously stirring. The reduced protein was mixed with $60 \mathrm{ml}$ cold buffer E $(0.1 \mathrm{M}$ Tris- $\mathrm{HCl}, 0.5 \mathrm{M}$ $\mathrm{NaCl}, 2 \mathrm{mM}$ EDTA, $\mathrm{pH}$ 8.0) for $48 \mathrm{~h}$ and dialyzed consecutively against buffer $\mathrm{E}\left(3 \mathrm{~L}, 48 \mathrm{~h}, 4^{\circ} \mathrm{C}\right)$ and buffer $\mathrm{F}$ (0.01 M Tris- $\left.\mathrm{HCl}, 0.15 \mathrm{M} \mathrm{NaCl}, \mathrm{pH} 8.0 ; 3 \mathrm{~L}, 24 \mathrm{~h}, 4^{\circ} \mathrm{C}\right)$. The dialyzed protein was concentrated in an Amicon stirred cell supplied with a PM-10 membrane (MW cutoff $10 \mathrm{kDa}$ ) and passed through a Superdex ${ }^{\mathrm{Tm}} 200$ 10/30 column (Amersham Pharmacia Biotech) with buffer F. The purified protein was analyzed by SDS PAGE.

\section{Isolation of peripheral blood mononuclear cell (PBMC) from blood}

The total of $198 \mathrm{ml}$ blood used in this study was obtained from 8 healthy volunteers with the age of 25 to 35 years old. Informed consent was obtained and the ethical approval was granted from Committee on Health Research Ethics of the Mochtar Riady Institute for Nanotechnology. To obtain monocytes as progenitor cell for generating MDDC, we used vacutainer ${ }^{\circledR}$ with heparin (BD vacutainer) during the phlebotomy procedure. PBMC were then prepared using Ficoll-hypaque (GE Health Care, UK) density gradient separation of phlebotomy products.

\section{Generation of monocyte-derived dendritic cell (MDDC)}

MDDC were generated as described previously [17] with some modifications. In brief, PBMC were adhered to 12 well culture plates with density $1 \times 10^{6} \mathrm{ml}^{-1}$ for $30 \mathrm{~min}$ at $37^{\circ} \mathrm{C}$ with $5 \% \mathrm{CO}_{2}$. The non adherent cells were removed by gentle wash and the adherent cells were then cultured in complete medium [RPMI 1640 (Sigma) supplemented with $10 \%$ heat-inactivated fetal bovine serum (Gibco), and contained rh-GM-CSF $(800 \mathrm{U} / \mathrm{ml}$, BD Bioscience Pharmingen) and rh-IL-4 $(1000 \mathrm{U} / \mathrm{ml}$, BD Bioscience Pharmingen]. Where indicated, purified human cord blood AFP (FL-AFP, purity > 95\%; Monobind method; Lee Biosolutions, Inc) or each D-AFP was added at day 0 for both immature and mature MDDC stage. Culture was fed with complete medium on day 3 and day 5 . The immature MDDC analysis was performed at day 6 by collecting the non-adherent cell from each group. Mature MDDC were obtained by transferring the non-adherent cell to another fresh 12 well plates and LPS 500ng/ml (Sigma Aldrich) was then added to induce MDDC maturation. Forty-eight hours later, the non-adherent cell from each group were collected and used for analysis. Each culture supernatant 
was stored at $-20^{\circ} \mathrm{C}$ for assessment of secreted cytokine within 1 month later.

\section{Analysis of MDDC surface markers and viability}

Monocytes, immature and mature MDDC were stained with CD14 PE (M5E2), HLA-DR FITC (G46-6), CD11cPE (B-ly6), CD86-PE (2331 FUN-1), CD80-FITC (L307.4), CD40 FITC (5C3), CD83-PE (Hb15e) and relevant isotype control (BD Bioscience Pharmingen), for 30 minutes at $4^{\circ} \mathrm{C}$. The cells were then washed with PBS containing 1\% FBS. For cell viability determination, cells were stained with Propidium Iodide (PI) at final concentration $1 \mu \mathrm{g} / \mathrm{ml}$. The cells were then analyzed within 24 hrs on FACS Epic Altra (Beckman Coulter) and gated according to their size (forward light scatter) and granularity (side light scatter).

\section{Quantitative measurement of secreted IL-12 by enzyme- linked immunosorbent assay (ELISA)}

To observe the ability of mature MDDC to produce IL-12, stored supernatants from whether immature or mature MDDC cultures were thawed and analyzed with the Human IL-12(p70) ELISA Set (BD Bioscience) according to the manufacturer's instruction with detection range between 7.8-500 $\mathrm{pg} / \mathrm{ml}$.

\section{Statistical analysis}

The DC surface marker expression was analyzed using EXPO32 ADC Analysis Software (Beckman Coulter). One way ANOVA (Tukey test) was used to compare more than two independent groups.

\begin{abstract}
Acknowledgements
We thank to all persons who kindly participate and contribute to this study, in particular the blood donors. We also express our deepest gratitude to Dr. Gerald J. Mizejewski, Dr. Astar Winoto and Dr. David Vaux for their encouragement and help. This research was supported by a grant from Mochtar Riady Institute for Nanotechnology.

\section{Authors' contributions \\ AS participated in experimental design and implementation. ADB was involved in generation of DC, Flow cytometry analysis, ELISA, and statistical analysis SP was involved in domains-AFP production experimental technique. IB was involved in domains-AFP purification experimental technique. MRA was involved in generation of DC, Flow cytometry analysis, ELISA, and statistical analysis. IF contributed in domains-AFP production. GA carried out domains-AFP purification. AU was involved in experimental technique. ST conceived the study and coordination. All authors read and approved the final manuscript.}

Received: 20 May 2010 Accepted: 17 January 2011

Published: 17 January 2011

\section{References}

1. Mizejewsky GJ: Alpha-fetoprotein (AFP)-derived peptides as epitopes for hepatoma immunotherapy: a commentary. Cancer Immunol Immunother 2009, 58:159-70.

2. Morinaga T, Sakai M, Wegmann TG, Tamaoki: Primary structures of human a-fetoprotein and its mRNA. Proc Natl Acad Sci USA 1983, 80:4604-8.
3. Alisa A, Ives A, Pathan AA, Navarrete CV, Williams R, Bertoletti A Behboudi S: Analysis of CD4+ T-Cell responses to a novel alphafetoprotein-derived epitope in hepatocellular carcinoma patients. Clin Cancer Res 2005, 11:6686-94.

4. Um SH, Catherine M, Akeel A, Annette Rl, John K, Roger W, Antonio B, Shahriar B: Alpha Fetoprotein impairs APC function and induces their apoptosis. J Immunol 2004, 173:1772-8.

5. Posypanova GA, Gorokhovets NV, Makarov VA, Savvateeva LV, Kireeva NN, Severin SE, Severin ES: Recombinant alpha-fetoprotein C-terminal fragment: the new recombinant vector for targeted delivery. J Drug Target 2008, 16:321-8.

6. Sigal $L$, Reiser $H$, Rock KL: The role of B7-1 and B7-2 costimulation for the generation of CTL responses in vivo. J Immunol 1998, 161:2740-5.

7. Grewal IS, Flavell RA: CD40 and CD154 in cell-mediated immunity. Annu Rev Immunol 1998, 16:111-35

8. Schönbeck U, Libby P: The CD40/CD154 receptor/ligand dyad. Cell Mol Life Sci 2001, 58:4-43.

9. Quezada SA, Jarvinen LZ, Lind EF, Noelle RJ: CD40/CD154 interactions at the interface of tolerance and immunity. Annu Rev Immunol 2004, 22:307-28

10. Miga A, Masters S, Gonzalez M, Noelle RJ: The role of CD40-CD154 interactions in the regulation of cell mediated immunity. Immunol Invest 2000, 29:111-4

11. Zobywalsky A, Javorovic M, Frankenberger B, Pohla H, Kremmer E, Bigalke I, Schendel DJ: Generation of clinical grade dendritic cells with capacity to produce biologically active IL-12p70. J Transl Med 2007, 5:18.

12. Pulendran B, Kumar P, Cutler CW, Mohamadzadeh M, Van Dyke T, Banchereau J: Lipopolysaccharides from distinct pathogens induce different classes of immune responses in vivo. J Immunol 2001, 167:5067-76

13. Leong SSJ, Middelberg APJ: The refolding of different a-fetoprotein variants. Protein Sci 2006, 15:2040-50

14. Heiser A, Coleman D, Dannull J, Yancey D, Maurice MA, Lallas CD, Dahm P, Niedzwiecki D, Gilboa E, Vieweg J: Autologous dendritic cells transfected with prostate-specific antigen RNA stimulate CTL responses against metastatic prostate tumors. J Clin Invest 2002, 109:409-17.

15. Vollmer CM, Eilber FC, Butterfield LH, Ribas A, Dissette VB, Koh A, Montejo LD, Lee MC, Andrews KJ, McBride H, Glaspy J, Economouz JS: -Fetoprotein-specific genetic immunotherapy for hepatocellular carcinoma. Cancer Res 1999, 59:3064-7.

16. Butterfield LH, Koh A, Meng W, Vollmer CM, Ribas A, Dissette V, Lee E, Glaspy JA, McBride WH, Economou JS: Generation of human T-cell responses to an HLA-A2.1-restricted peptide epitope derived from alpha-fetoprotein. Cancer Res 1999, 59:3134-42.

17. Ghanekar S, Bhatia S, Ruitenberg JJ, Dela Rosa C, Disis ML, Maino VC, Maecker HT, Waters CA: Phenotype and in vitro function of mature MDDC generated from cryopreserved PBMC of cancer patients are equivalent to those from healthy donors. J Immunother Based Ther Vaccines 2007, 5:7

doi:10.1186/1471-2172-12-4

Cite this article as: Setiyono et al:: Immunoregulatory effects of AFP domains on monocyte-derived dendritic cell function. BMC Immunology 2011 12:4

\section{Submit your next manuscript to BioMed Central and take full advantage of:}

- Convenient online submission

- Thorough peer review

- No space constraints or color figure charges

- Immediate publication on acceptance

- Inclusion in PubMed, CAS, Scopus and Google Scholar

- Research which is freely available for redistribution 